University of Nebraska - Lincoln

DigitalCommons@University of Nebraska - Lincoln

\title{
Molecular Diagnostic for Boll Weevil (Coleoptera: Curculionidae) Based on Amplification of Three Species-Specific Microsatellites
}

Kyung Seok Kim

USDA-ARS

Zofia Szendrei

Rutgers University

Cesar Rodriguez-Saona

Rutgers University

Phillip G. Mulder Jr.

Oklahoma State University

Thomas W. Sappington

USDA-ARS, tsapping@iastate.edu

Follow this and additional works at: https://digitalcommons.unl.edu/usdaarsfacpub

Part of the Agricultural Science Commons

Kim, Kyung Seok; Szendrei, Zofia; Rodriguez-Saona, Cesar; Mulder, Phillip G. Jr.; and Sappington, Thomas W., "Molecular Diagnostic for Boll Weevil (Coleoptera: Curculionidae) Based on Amplification of Three Species-Specific Microsatellites" (2009). Publications from USDA-ARS / UNL Faculty. 736.

https://digitalcommons.unl.edu/usdaarsfacpub/736

This Article is brought to you for free and open access by the U.S. Department of Agriculture: Agricultural Research Service, Lincoln, Nebraska at DigitalCommons@University of Nebraska - Lincoln. It has been accepted for inclusion in Publications from USDA-ARS / UNL Faculty by an authorized administrator of DigitalCommons@University of Nebraska - Lincoln. 


\title{
Molecular Diagnostic for Boll Weevil (Coleoptera: Curculionidae) Based on Amplification of Three Species-Specific Microsatellites
}

\author{
KYUNG SEOK KIM, ${ }^{1,2,3}$ ZSOFIA SZENDREI,${ }^{3,4}$ CESAR RODRIGUEZ-SAONA, ${ }^{4}$ \\ PHILLIP G. MULDER, JR., ${ }^{5}$ AND THOMAS W. SAPPINGTON ${ }^{1,6}$
}

\begin{abstract}
J. Econ. Entomol. 102(2): 759-766 (2009)
ABSTRACT The boll weevil, Anthonomus grandis grandis Boheman (Coleoptera: Curculionidae), is a serious pest of cultivated cotton, Gossypium hirsutum L., in the Americas, and reinfestation of zones from which they have been eradicated is of perpetual concern. Extensive arrays of pheromone traps monitor for reintroductions, but occasionally the traps collect nontarget weevils that can be misidentified by scouts. For example, the congeneric pepper weevil, Anthonomus eugenii Cano, and other superficially similar weevils are attracted to components of the boll weevil lure or trap color. Although morphologically distinguishable by trained personnel, the potential for misidentification is compounded when captured weevils are dismembered or partially consumed by ants or ground beetles that sometimes feed on them in the traps. Because misidentification can have expensive consequences, a molecular diagnostic tool would be of great value to eradication managers. We demonstrate that a cocktail of three primer pairs in a single polymerase chain reaction (PCR) amplify species-specific microsatellites that unambiguously distinguish the boll weevil from three other weevil species tested, including pepper weevil; cranberry weevil, Anthonomus eugenii musculus Say; and pecan weevil, Curculio caryae Horn. However, it does not distinguish the boll weevil from the subspecific "thurberia" weevil. A universal internal transcribed spacer primer pair included in the cocktail cross-amplifies DNA from all species, serving as a positive control. Furthermore, the diagnostic primers amplified the target microsatellites from various boll weevil adult body parts, indicating that the PCR technology using the primer cocktail is sensitive enough to positively identify a boll weevil even when the body is partly degraded.
\end{abstract}

KEY WORDS Anthonomus grandis, boll weevil, molecular diagnostic, eradication, microsatellites

The boll weevil, Anthonomus grandis grandis Boheman (Coleoptera: Curculionidae), is one of the most destructive pests of cultivated cotton, Gossypium hirsutum L., in the Americas. Since initiation of the first eradication program in 1978, the boll weevil has been eliminated from several states in the southeastern and southwestern United States (Smith 1998, Carter et al. 2001, El-Lissy and Grefenstette 2006), but eradication is ongoing in parts of seven U.S. states and northern Mexico. In Texas, the boll weevil eradication program was initiated in 1995, and 17 zones are currently in

Mention of trade names or commercial products in this article is solely for the purpose of providing specific information and does not imply recommendation or endorsement by the U.S. Department of Agriculture.

${ }^{1}$ USDA-ARS Corn Insects and Crop Genetics Research Unit, Genetics Laboratory, Iowa State University, Ames, IA 50011.

${ }^{2}$ Current address: College of Veterinary Medicine, Seoul National University, Sillim-dong San 56-1, Gwanak-gu, Seoul 151-742, South Korea.

${ }^{3}$ These authors contributed equally to this work.

${ }^{4}$ Marucci Center for Cranberry and Blueberry Research and Extension, Department of Entomology, Rutgers University, Chatsworth, NJ 08019 .

${ }_{5}^{5}$ Department of Entomology and Plant Pathology, 127 NRC, Oklahoma State University, Stillwater, OK 74078.

${ }^{6}$ Corresponding author, e-mail: tom.sappington@ars.usda.gov. different stages. The boll weevil has been eradicated from several zones in central and western Texas, but seven others remain infested to varying degrees. After eradication has been declared complete by authorities for a particular zone, a posteradication maintenance program is initiated whereby a systematic array of pheromone traps is deployed and regularly monitored for reintroductions.

The ability of boll weevil adults to disperse hundreds of kilometers is well-documented (Guerra 1988; Spurgeon et al. 1997; Kim and Sappington 2004a,b, 2006; Kim et al. 2006; Westbrook et al. 2007), and both natural dispersal by flight (Culin et al. 1990, Westbrook et al. 2007) and human-mediated transport (Sappington et al. 2004, 2006; Kim et al. 2008) can reintroduce boll weevils to an eradication zone. The threat of reintroduction is a constant concern because of the expense involved in eliminating a colonizing population that successfully establishes (Kim et al. 2006, Westbrook et al. 2007, Kiser and Catanach 2008). A population genetics approach using neutral molecular DNA markers has provided important clues to the origin of boll weevils captured unexpectedly in or near eradication zones (Kim et al. 2006, 2008). In most cases 
Table 1. Collection details of weevil specimens assayed in this study

\begin{tabular}{llcl}
\hline \hline Common name & \multicolumn{1}{c}{ Location } & Collection date & Collector \\
\hline Boll weevil & Weslaco, TX & 5 June 2000 & T. Sappington, USDA-ARS \\
& Tampico, Mexico & 7 April 1999 & S. Greenberg, USDA-ARS \\
& Tlahualilo, Mexico & P. Cano-Ríos, INIFAP & Oct. 2004 \\
Thurberia weevil & Laveen, AZ & 2 Jan. 1989 Roehrdanz, USDA-ARS \\
Cranberry weevil & Molins Basin, AZ & 30 April 1996 & R. Roehrdanz, USDA-ARS \\
Pepper weevil & Blueberry farms, central NJ & 20 April 2008 & Z. Szendrei, Rutgers University \\
Pecan weevil & University of Florida colony & 28 Feb. 2008 & K. Addesso, University of Florida \\
\hline
\end{tabular}

the response is swift, massive, disruptive, and expensive to the program and to the affected growers.

A cornerstone of the eradication and the posteradication maintenance program is the pheromone trap (Smith 1998, Sappington and Spurgeon 2000, Spurgeon 2003, Spurgeon and Raulston 2006), which is baited with an aggregation pheromone that attracts both sexes (Hardee et al. 1969, Tumlinson et al. 1971). Although the lure is fairly specific to the boll weevil, it contains components attractive to a wide range of other curculionids (Tóth et al. 2007), including the pepper weevil, Anthonomus eugenii Cano (Eller et al. 1994), and the pecan weevil, Curculio caryae Horn (Hedin et al. 1997). Pepper weevils are frequently captured in boll weevil traps, perhaps through crossattraction of pheromone, but also probably through attractiveness of trap color (Patrock et al. 1992). Other Anthonomus spp. and more distantly related weevil species may be attracted to unbaited boll weevil traps as well (Clark 1988, Bloem et al. 2002).

The consequences of misidentifying a trapped insect can be costly. A false positive, i.e., misidentifying a nontarget as a boll weevil, could trigger unnecessary and costly program responses such as multiple insecticide treatments of cotton fields within a severalkilometer radius of the trap. In most cases, nontarget weevils in a trap can be easily distinguished from boll weevils morphologically. However, pepper weevils can be problematic and are the most likely to be mistaken for boll weevils. They are about half the size of a boll weevil, but the latter can be quite small, too, if the larva matured on a poor quality diet (Reardon and Spurgeon 2002, Greenberg et al. 2005). The number of spines on the femur of the foreleg is diagnostic but requires magnification and a trained eye to assess. Because of the cost involved in a full-blown reaction to a reintroduction, the public demands reassurance that there was no mistake in a subjective visual identification, which puts pressure on the eradication program to have a credible independent taxonomist make the call.

A false negative, i.e., failing to recognize a boll weevil, risks increased expense as well, because it becomes more difficult to eliminate a population the longer it goes undetected. This class of error can occur if an unusually small boll weevil is mistaken for a pepper weevil but is most likely to occur when morphological features are compromised. The body of a trapped weevil is sometimes dismembered and broken up by ants or ground beetles that enter traps and feed on the weevils. After expiring in the trap, a weevil can become brittle by baking in the sun for several days before collection and thus can easily break into unrecognizable pieces during removal from the trap or during transfer to the lab. A disintegrated boll weevil may still be identified by the morphology of its parts, but the level of uncertainty increases substantially.

For all of these reasons, a less subjective but rapid diagnostic method is needed to positively identify a boll weevil when it is captured, and to definitively exclude any nontarget weevils that may be captured accidentally. Molecular DNA makers have enjoyed wide use for diagnostic purposes within and between species in insects (Collins and Paskewitz 1996, Hoogendoorn and Heimpel 2001). Polymerase chain reaction (PCR)-based analysis allows assays of small amounts of DNA from individual insects as well as permitting high throughput of large numbers of samples. Here, we present a PCR-based molecular diagnostic method for determining whether an insect collected in a boll weevil trap is truly a boll weevil. It relies on multiplex amplification of three microsatellite loci developed specifically for boll weevil (Kim and Sappington 2004b). Our reasoning for testing microsatellites as diagnostic for boll weevil is based on the unique characteristics of this class of marker. Microsatellites are short tandem repeats of simple nucleotide sequence, inherited in a Mendelian fashion, and evenly distributed in the genome. Although we cannot test every possible nontarget, our premise is that because microsatellites are usually species specific (Zane et al. 2002, Selkoe and Toonen 2006), it is extremely unlikely that three different boll weevil loci would all cross-amplify in a nontarget species. In particular, we hypothesized that although all three loci would amplify in the boll weevil and the subspecific thurberia weevil, Anthonomus g. thurberiae Pierce, none would amplify in three representative nontarget weevils: the pecan weevil, and the more closely related pepper weevil and cranberry weevil, Anthonomus musculus Say. We also demonstrate that this method can be used to assay weevil specimens that have been damaged.

\section{Materials and Methods}

Weevil Specimens. Three representative weevil species that overlap in geographic distribution with the boll weevil were tested in this study (Table 1 ), including the cranberry weevil, pepper weevil, and 


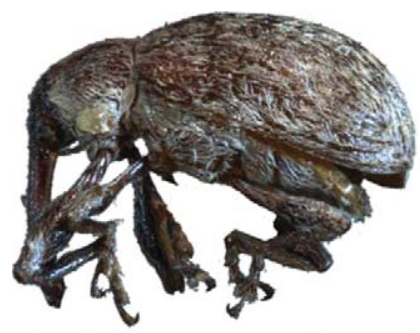

A. Anthonomus grandis grandis

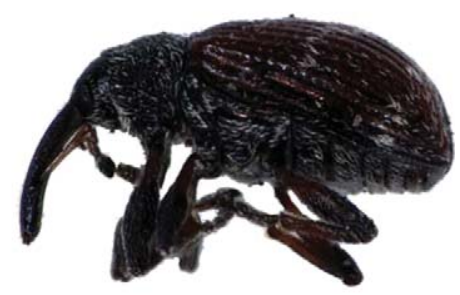

B. Anthonomus musculus

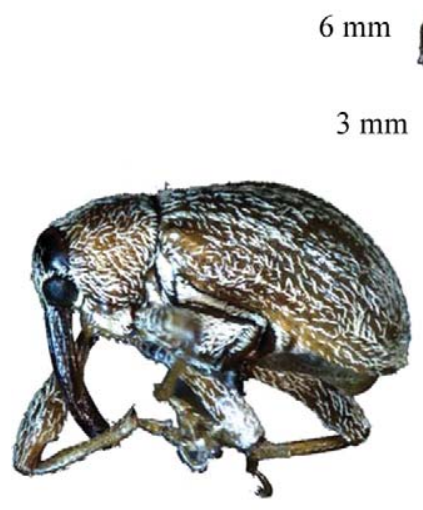

C. Anthonomus eugenii

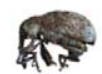

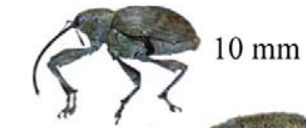

$2 \mathrm{~mm}$

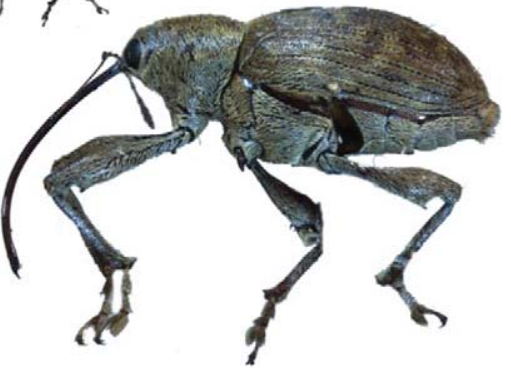

D. Curculio caryae

Fig. 1. Photographs of the four weevil species (Coleoptera: Curculionidae) tested with boll weevil diagnostic markers. Reduced images in center are shown to scale to illustrate relative size differences. Approximate body length indicated next to central images. Photographs taken with Leica MZ16 Stereomicroscope and imaged by Image-Pro Plus software (Media Cybernetics, Inc., Bethesda, MD). Photographs courtesy of Rutgers University Entomological Museum. (Online figure in color.)

pecan weevil (Fig. 1). In addition, a subspecies of the boll weevil called the thurberia weevil was tested as well. Most of the boll weevils were collected from the United States and northern Mexico in previous studies (Kim and Sappington 2004a, Kim et al. 2006), but one tested individual was collected nearly $20 \mathrm{yr}$ ago from a population in southern Arizona, which has since been eradicated. Samples from the other weevil species were collected specifically for this study (Table 1). Pepper weevil specimens were obtained from a laboratory colony maintained at the University of Florida (Gainesville, FL), and cranberry weevils were collected from commercial blueberry fields in central New Jersey in 2008.

DNA Extraction. Boll weevil and pecan weevil DNA extraction was conducted at the USDA-ARS Corn Insects and Crop Genetics Research Unit (USDA-ARS, Ames, IA) and that of cranberry and pepper weevils was conducted at the P. E. Marucci Center for Blueberry and Cranberry Research and Extension (Rutgers, The State University of New Jersey, Chatsworth, NJ). Genomic DNA from all weevil species was extracted using the Puregene Core kit (QIAGEN, Valencia, CA) according to the manufacturer's protocol. In addition to individual whole body extractions, DNA was extracted from boll weevil body parts including head, pairs of elytra, pairs of hind wings, all legs combined, thorax, and abdomen.
Diagnostic Markers. We used the primer pairs for microsatellite markers AG-D7, AG-D10, and AG-D12, which were developed previously for A. g. grandis (Kim and Sappington 2004b). These loci were selected because they are compatible in multiplex PCR and are sufficiently different in size to be clearly separated on an agarose gel. In addition to the microsatellite primers, universal primers were included in the multiplex reaction to amplify the internal transcribed spacer (ITS) locus. These included a combination of ITS4 (TCCTCCGCTTATTGATATGC) and ITS5 (GGAAGTAAAAGTCGTAACAAGG) primers (White et al. 1990). Because it should amplify in all insect species, ITS serves as a positive control for the integrity of the genomic DNA template and reaction conditions.

Polymerase Chain Reaction and Electrophoresis. We performed various PCR experiments to verify that the three selected A. grandis microsatellite markers are indeed specific for $A$. grandis, and that the ITS marker is amplified by universal ITS $4+5$ primers in all four weevil species tested. In addition, DNA was amplified from each of six body parts dissected from a boll weevil adult to determine whether this diagnostic molecular tool is sensitive enough to assay dismembered pieces of the adult body.

Multiplex PCR amplifications were carried out with the cocktail of four primer sets using the Multilocus Amplification kit (QIAGEN) in a 10- $\mu$ l volume con- 
taining $1 \times$ QIAGEN multiplex PCR Master Mix (providing a final concentration of $3 \mathrm{mM} \mathrm{MgCl} 2$ ), $0.2 \mu \mathrm{M}$ each primer for multiplex, and $2 \mu \mathrm{l}$ of genomic DNA (15 ng DNA per reaction). Touchdown cycling conditions were used as follows: an initial denaturing step at $94^{\circ} \mathrm{C}$ for $15 \mathrm{~min}$; seven touchdown cycles starting at $94^{\circ} \mathrm{C}$ for $30 \mathrm{~s}, 67^{\circ} \mathrm{C}$ for $90 \mathrm{~s}, 72^{\circ} \mathrm{C}$ for $60 \mathrm{~s}$, with annealing temperature decreasing by $2^{\circ} \mathrm{C}$ per cycle to a temperature of $53^{\circ} \mathrm{C}$; followed by a further 25 cycles at $94^{\circ} \mathrm{C}$ for $30 \mathrm{~s}, 53^{\circ} \mathrm{C}$ for $90 \mathrm{~s}, 72^{\circ} \mathrm{C}$ for $60 \mathrm{~s}$; and a final extension at $60^{\circ} \mathrm{C}$ for $30 \mathrm{~min}$. Conditions for amplification of single markers was the same as the multiplex PCR conditions except that each primer was present at $0.4 \mu \mathrm{M}$.

Amplification products were visualized by electrophoresis of $7 \mu \mathrm{l}$ of the reaction solution loaded onto $2 \%$ agarose gels in $1 \times$ Tris borate-EDTA buffer in the presence of $0.1 \mu \mathrm{g} / \mathrm{ml}$ ethidium bromide. Resulting bands were sized by comparison with 100-bp DNA ladder (Invitrogen, Carlsbad, CA) or MspI-digested pGEM vector size standards run concomitantly on the gel. Gels were photographed with a Chemi Doc System (Bio-Rad, Hercules, CA) or an AlphaImager (Alpha Innotech Corporation, San Leandro, CA).

Analysis of Results. We tested the following specific hypotheses: 1) The microsatellite loci AG-D7, AGD10, and AG-D12 will amplify only in boll weevil (including both subspecies A. g. grandis and A. g. thurberiae), and these loci are not present in pepper weevil, cranberry weevil, and pecan weevil. 2) All three microsatellite loci will amplify from separate body parts of dismembered weevils. We know from previous studies involving whole body samples of $>700$ individual A. grandis grandis from 22 populations in the United States and Mexico that these three loci are present in this species and always amplify under appropriate PCR conditions (Kim and Sappington 2004b, 2006; Kim et al. 2006, 2008). We had not previously tested these loci in $A$. g. thurberiae, but we suspected that they would amplify because, as a subspecies of A. g. grandis, they are evolutionarily closely related.

The first hypothesis can be accepted if the three microsatellite loci, which are present in boll weevil (Kim and Sappington 2004b, 2006; Kim et al. 2006, 2008), are not present in pepper weevil, cranberry weevil, and pecan weevil. Acceptance of this hypothesis would indicate that this set of markers can be used to diagnose an individual as either a boll weevil, or not a boll weevil. It cannot, and is not designed to, identify an individual as a pepper weevil, cranberry weevil, or pecan weevil-we simply tested these as representative closely related weevil species that might be encountered as nontargets in a boll weevil trap. Note that presence or absence of a locus is a species-level character (Primmer et al. 1996, Baliraine et al. 2003) and does not vary between populations or between individuals within a species. Allelic variation is irrelevant, because there are no alleles for a locus that does not exist. Thus, a single individual per nontarget species from any location or population is sufficient to test this hypothesis, and no statistical analysis is needed or

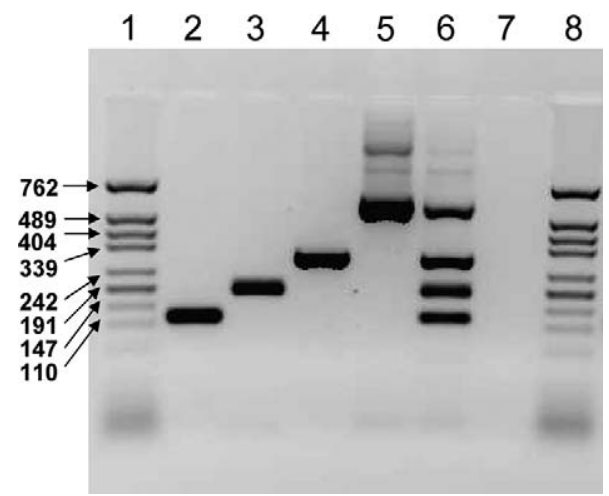

Fig. 2. PCR amplification of boll weevil DNA using the four genomic primer pairs alone: AG-D7 (2), AG-D10 (3), AG-D12 (4), ITS4 + 5 (5); and the four primer pairs in a multiplex cocktail with (6) and without (7) DNA template. DNA size standard: pGEM-MspI ladder $(1,8)$.

relevant. Nevertheless, we tested 17 cranberry weevils, six pepper weevils, eight pecan weevils, and seven thurberia weevils over the course of this study to go along with the $700+$ boll weevils tested in previous studies, and the results were invariable.

Presence or absence of a locus is easily determined by whether the primers amplify a product through PCR in the expected size range, the results of which can be determined unambiguously by simple visual examination of the stained gels for the expected presence/absence banding patterns. The ITS locus is present in all insects, so it is expected to amplify a $\approx 600$-bp product in every reaction regardless of species. If it does not, the absence of microsatellite products cannot be taken to indicate absence of those loci. Instead, it indicates that there was something wrong with some part of the PCR reaction conditions or that the extracted DNA was too degraded to serve as template. As long as the positive control, ITS, amplifies, an absence of the three microsatellite bands indicates those loci are not present in that individual, and therefore 1) that individual belongs to a species where those loci do not exist and 2) that individual is not a boll weevil. The first hypothesis is designed to test the corollary that if the three microsatellite bands are present, it is a boll weevil.

\section{Results}

PCR using individual marker primers and boll weevil DNA template successfully produced a unique amplification product for each marker: $120 \mathrm{bp}$ for AG-D7, $190 \mathrm{bp}$ for AG-D10, $290 \mathrm{bp}$ for AG-D12, and $\approx 600 \mathrm{bp}$ for ITS (Fig. 2). Each amplification product generated with the microsatellite primers was consistent with its expected size range as reported from a natural boll weevil population (Kim and Sappington 2004b) and as encountered in subsequent surveys involving 22 populations over a large geographic area including eight U.S. states, and northern Mexico (Kim and Sappington 2006; Kim et al. 2006, 2008). There was no apparent 


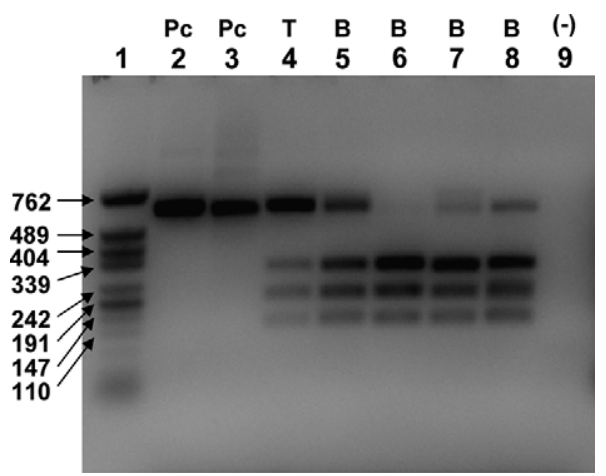

Fig. 3. PCR profile of weevils using a multiplex cocktail of primers to amplify three diagnostic microsatellites (100$300 \mathrm{bp}$ ) and an ITS $4+5$ positive control. DNA size standards: pGEM-MspI ladder $(1)$, pecan weevil $(2,3 ; \mathrm{Pc})$, thurberia weevil (4; T), boll weevil (B): Laveen, AZ (5), Tampico, Mexico (6), Weslaco, TX (7), Tlahualilo, Mexico (8); no DNA template $[9,(-)]$.

interference or cross-amplification among the four primer sets. A multiplex cocktail of all four genomic marker primer pairs simultaneously generated the four expected PCR amplicons from boll weevil DNA template (Fig. 2). The cocktail of primers also successfully amplified DNA from the subspecific thurberia weevil (Fig. 3). However, for the pecan weevil (Fig. 3) and the congeneric pepper and cranberry weevils (Fig. 4), no amplification product was observed for any of the three boll weevil microsatellite markers, demonstrating that these loci are not present in these species. The ITS $4+5$ primers always generated a strong 600 -bp amplification product for DNA extracted from fresh weevil specimens, but only a weak product was generated from the DNA of a boll weevil collected in Tampico, Mexico, 6 yr previously (Fig. 3, lane 6). Nevertheless, the boll weevil microsatellite marker primers generated the expected amplification products for this specimen, suggesting these markers are relatively insensitive to partial DNA degradation.

In the other Anthonomus species, the ITS4 + 5 primers generated additional higher-molecular-weight amplifi-

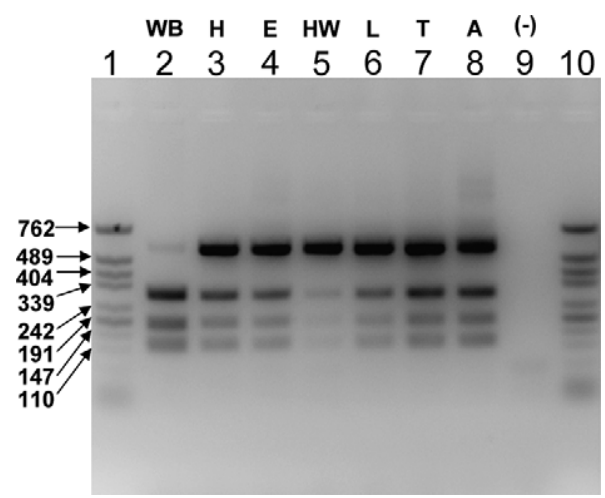

Fig. 5. PCR amplification of body parts dissected from a boll weevil adult using a cocktail of primers to amplify three diagnostic microsatellites (100-300 bp) and an ITS $4+5$ positive control. Whole body $(2 ; \mathrm{WB})$, head $(3 ; \mathrm{H})$, elytra $(4$; $\mathrm{E})$, hind wings $(5 ; \mathrm{HW})$, legs $(6 ; \mathrm{L})$, thorax $(7 ; \mathrm{T})$, abdomen (8; A), no DNA template [9, (-) ], DNA size standard: pGEMMspI ladder $(1,10)$.

cation products along with the expected 600-bp ITS product (Fig. 4, lanes $2-8$ and 20-26). One was a PCR product of $\approx 750 \mathrm{bp}$ that amplified in some of the cranberry weevils (e.g., lanes 3, 5, 21, and 23). Another product of $\approx 900 \mathrm{bp}$ consistently amplified in all pepper weevils tested (e.g., lanes 6, 7, 24, and 25). When the three sets of microsatellite primers were combined in the absence of the ITS $4+5$ primers, they amplified only the three expected loci from boll weevil DNA template, and no higher weight products were produced (lanes 11-17), demonstrating that all of the observed bands $\geq 600 \mathrm{bp}$ were generated by the ITS primers, not the microsatellite primers. The pattern produced for boll weevil by the full cocktail of four genomic primers (lane 26) was the same as that obtained combining results of the ITS $4+5$ primers alone (lane 8 ) and the microsatellite primer cocktail alone (lane 17).

All three microsatellite markers and the ITS positive control were successfully amplified from DNA extracted from each type of body part (Fig. 5). The microsatellite amplicons from the hind wings were relatively weak, but still clearly visible (Fig. 5, lane 5).

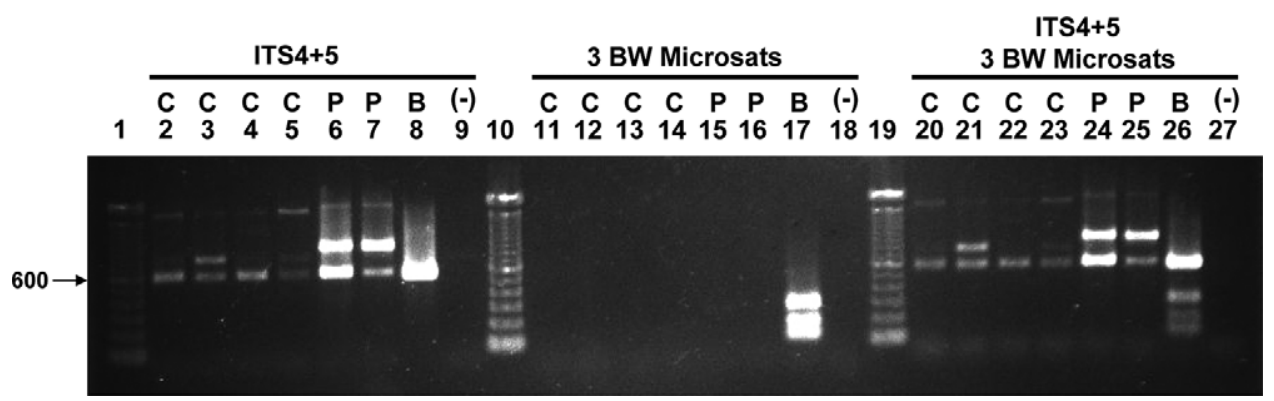

Fig. 4. PCR profiles of three Anthonomus species using ITS4 + 5 primers alone (2-9), a cocktail of primers to amplify three diagnostic boll weevil microsatellites (100-300 bp: AG-D7, AG-D10, AG-D12) (11-18), and a cocktail of both ITS4 + 5 and microsatellite primers (20-27). 100-bp ladder DNA size standards (1, 10, 19), cranberry weevil $(\mathbf{C}, 2-5,11-14,20-23)$, pepper weevil (P, 6-7, 15-16, 24-25), boll weevil (B, 8, 17, 26), no DNA template [ (-), 9, 18, 27]. 


\section{Discussion}

The PCR and electrophoresis methods used in this study are simple, rapid, and reproducible, and the results were consistent between the ARS and Rutgers University laboratories. The four amplification products generated from boll weevils with a cocktail of diagnostic-marker primers were easily discernible on an agarose gel such that the products can be scored unambiguously based on their relative size. The additional high weight amplification products for the pepper and cranberry weevils (Fig. 4) are generated by the ITS $4+5$ primers, perhaps through amplification of multiple copies of the spacer differing in the number of repeat units (Collins and Paskewitz 1996). Inter- and intraspecies heterogeneity of ribosomal DNA has been reported in insects (Collins and Paskewitz 1996, Onyabe and Conn 1999). Nevertheless, these additional amplification products did not introduce any ambiguity in interpreting the PCR products diagnostic for boll weevil and therefore can be ignored for the purposes of this assay. Together, our findings indicate that the three microsatellite markers are diagnostic for boll weevil, and readily distinguish this species from the other Anthonomus and curculionid species tested, and that the ITS $4+5$ primers can be used as a positive control across species.

There are previous reports of microsatellite primers cross-amplifying DNA from closely related species (Grasela and McIntosh 2005, Kim and Sappington 2005), or even species from a different genus (Wilson et al. 2004, Weng et al. 2007), but this was not observed for any of the microsatellites in the Anthonomus species tested or the more distantly related pecan weevil (Figs. 3 and 4). The three microsatellites cross-amplified in A. g. thurberiae, a morphologically indistinguishable subspecies of A. grandis. It differs behaviorally from A. g. grandis, feeding mainly on wild cotton, Gossypium thurberi Todaro, in the southwestern United States and northwestern Mexico (Burke et al. 1986, Roehrdanz 2001) and is not considered a pest of cultivated cotton. Although our assay will not distinguish A. g. grandis from A. g. thurberiae, most of the time this will not be an issue because of the restricted geographic range of the latter. Furthermore, a molecular diagnostic assay was developed by Roehrdanz (2001), which can be used in parallel on the same specimens if the presence of thurberia weevils is considered a possibility in a given sample.

Microsatellite markers are widely used to characterize genetic variation within and between populations, in part because of their high polymorphism deriving from differences in the number of short sequence repeats (Zhang 2004). Variation among alleles is possible to detect using polyacrylamide gel electrophoresis. However, unless the size differences are large, they are practically undetectable by agarose gel electrophoresis because agarose gels are not sensitive enough to discriminate DNA fragments differing by a few base pairs. Therefore, even though there is substantial allelic variation among individual boll weevils at the microsatellite loci used in this study (Kim and
Sappington 2004b, 2006; Kim et al. 2006), it has a negligible effect on amplicon size determination on the agarose gel used in our diagnostic assay, where a single band is generated for each microsatellite locus regardless of the allele(s) involved.

A potential impediment to using microsatellites as diagnostic markers is the possible presence of null alleles (Liewlaksaneeyanawin et al. 2002, Chapuis and Estoup 2007). Null alleles arise when a mutation in the primer binding site prevents PCR amplification. This issue is important in population genetics studies where accurate scoring of both alleles per individual is necessary. However, null alleles are less of a concern in our diagnostic assay because the lack of a band in a boll weevil (false negative) will occur only if an individual is homozygous null. Null alleles have not been detected for the three microsatellite loci used in this study in surveys of $>700$ boll weevils collected across wide geographic locations from Mexico and the southeastern United States (Kim and Sappington 2004b, 2006; Kim et al. 2006, 2008), making the probability of encountering a homozygous null individual extremely low. Moreover, the use of three sets of microsatellite primers together increases the chance for correctly identifying a boll weevil. Thus, even if a rare homozygous null allele genotype leads to no amplification at one microsatellite locus, the other two loci will still amplify and positively identify the specimen as a boll weevil.

Molecular diagnostics are particularly important in eradication contexts because of the costs of both false positives and false negatives. For example, random amplified polymorphic DNA markers (Skoda et al. 2002) and PCR-restriction fragment length polymorphism (Taylor et al. 1996) have been applied as identification tools for discriminating the screwworm, Cochliomyia hominivorax (Coquerel), a serious pest of livestock in the Western Hemisphere, from the secondary nonpest screwworm, Cochliomyia macellaria (F.). The informed management decisions these diagnostic tools make possible have contributed to the success of the New World screwworm eradication program (Skoda et al. 2002).

In conclusion, our PCR-based assay provides a simple, straightforward, and cost-effective diagnostic tool to correctly distinguish boll weevils from other weevil species that could potentially be confused with boll weevils and thus interfere with making appropriate eradication program decisions. This molecular diagnostic tool will provide high-confidence identification of boll weevils versus nontargets, enhancing accuracy over morphological assessment alone. It will be especially valuable for identifying damaged specimens, where identification by morphological characters becomes compromised. Although specimens should be frozen or otherwise properly stored until processing, the assay is quite robust even in the face of partially degraded DNA. The assay can be completed easily within $2 \mathrm{~d}$, allowing eradication personnel or action agencies to make timely decisions to eliminate new infestations. Of equal importance, this tool will reduce 
the chances of implementing unnecessary and expensive eradication efforts based on misidentifications.

\section{Acknowledgments}

We thank Lisa Fraser and Meghan Minner for excellent technical assistance in the DNA extraction. We also thank Shoil Greenberg, Pedro Cano-Ríos, and Richard Roehrdanz for providing boll weevils; Richard Roehrdanz for providing thurberia weevils; and Karla Addesso for providing pepper weevils. Thanks to Frank Carle at the Entomological Museum (Rutgers University) for providing specimens for photography and allowing access to the photographic equipment. Thanks to James Polashock (USDA-ARS) for access to his molecular laboratory at the Marucci Center (Chatsworth, $\mathrm{NJ}$ ).

\section{References Cited}

Baliraine, F. N., M. Bonizzoni, E. O. Osir, S. A. Lux, F. J. Mulaa, L. Zheng, L. M. Gomulski, G. Gasperi, and A. R. Malcrida. 2003. Comparative analysis of microsatellite loci in four fruit fly species of the genus Ceratitis (Diptera: Tephritidae). Bull. Entomol. Res. 93: 1-10.

Bloem, S. K., R. F. Mizell, and C. W. O'Brien. 2002. Old traps for new weevils: new records for curculionids, brentids and anthribids from Jefferson County Florida. Fla. Entomol. 85: 635-647.

Burke, H. R., W. E. Clark, J. R. Cate, and P. A. Fryxell. 1986. Origin and dispersal of the boll weevil. Bull. Entomol. Soc. Am. 32: 228-238.

Carter, F. L., T. C. Nelson, A. G. Jordan, and J. R. Smith. 2001. U.S. cotton declares war on the boll weevil, pp. 25-54. In W. A. Dickerson, A. L. Brashear, J. T. Brumley, F. L. Carter, W. J. Grefenstette, and F. A. Harris [eds.], 2001. Boll weevil eradication in the United States through 1999. The Cotton Foundation Publisher, Memphis, TN.

Chapuis, M. P., and A. Estoup. 2007. Microsatellite null alleles and estimation of population differentiation. Mol. Biol. Evol. 24: 621-631.

Clark, W. E. 1988. Revision of the furcatus species group of the weevil genus Anthonomus Germar (Coleoptera: Curculionidae). Coleop. Bull. 42: 359-377.

Collins, F. H., and S. M. Paskewitz. 1996. A review of the use of ribosomal DNA (rDNA) to differentiate among cryptic Anopheles species. Insect Mol. Biol. 5: 1-9.

Culin, J., S. Brown, J. Rogers, D. Scarborough, A. Swift, B. Cotterill, and J. Kovach. 1990. A simulation model examining boll weevil dispersal: historical and current situations. Environ. Entomol. 19: 195-208.

Eller, F. J., R. J. Bartelt, B. S. Shasha, D. J. Schuster, D. G. Riley, P. A. Stansly, T. F. Mueller, K. D. Shuler, B. Johnson, J. H. Davis, and C. A. Sutherland. 1994. Aggregation pheromone for the pepper weevil, Anthonomus eugenii Cano (Coleoptera, Curculionidae)-identification and field activity. J. Chem. Ecol. 20: 1537-1555.

El-Lissy, O. A., and W. J. Grefenstette. 2006. Progress of boll weevil eradication in the U.S., pp. 1266-1276. In Proceedings of the Beltwide Cotton Conferences, 3-6 January 2006, San Antonio, TX.

Grasela, J. J., and A. H. McIntosh. 2005. Cross-species investigation of Helicoverpa armigera microsatellites as potential markers for other related species in the $\mathrm{He}$ licoverpa-Heliothis complex. J. Insect Sci. 5: 47 (insectscience.org/5.47).

Greenberg, S. M., D. W. Spurgeon, T. W. Sappington, and M. Sétamou. 2005. Size-dependent feeding and reproduc- tion by boll weevil (Coleoptera: Curculionidae). J. Econ. Entomol. 98: 749-756.

Guerra, A. A. 1988. Seasonal boll weevil movement between northeastern Mexico and the Rio Grande Valley of Texas, USA. Southwest. Entomol. 13: 261-271.

Hardee, D. D., W. H. Cross, and E. B. Mitchell. 1969. Male boll weevils are more attractive than cotton plants to boll weevils. J. Econ. Entomol. 62: 165-169.

Hedin, P. A., D. A. Dollar, J. K. Collins, J. G. Dubois, P. G. Mulder, G. H. Hedger, M. W. Smith, and R. D. Eikenbary. 1997. Identification of male pecan weevil pheromone. J. Chem. Ecol. 23: 965-977.

Hoogendoorn, M., and G. E. Heimpel. 2001. PCR-based gut content analysis of insect predators: using ribosomal ITS-1 fragments from prey to estimate predation frequency. Mol. Ecol. 10: 2059-2067.

Kim, K. S., and T. W. Sappington. 2004a. Boll weevil (Anthonomus grandis, Boheman) (Coleoptera: Curculionidae) dispersal in the southern United States: evidence from mitochondrial DNA variation. Environ. Entomol. 33: $457-470$.

Kim, K. S., and T. W. Sappington. 2004b. Isolation and characterization of polymorphic microsatellite loci in the boll weevil, Anthonomus grandis Boheman (Coleoptera: Curculionidae). Mol. Ecol. Notes 4: 701-703.

Kim, K. S., and T. W. Sappington. 2005. Polymorphic microsatellite loci from the western corn rootworm (Insecta: Coleoptera: Chrysomelidae) and cross-amplification with other Diabrotica spp. Mol. Ecol. Notes 5: 115-117.

Kim, K. S., and T. W. Sappington. 2006. Molecular genetic variation of boll weevil populations in North America estimated with microsatellites: implications for patterns of dispersal. Genetica 127: 143-161.

Kim, K. S., P. Cano-Ríos, and T. W. Sappington. 2006. Using genetic markers and population assignment techniques to infer origin of boll weevils (Coleoptera: Curculionidae) unexpectedly captured near an eradication zone in Mexico. Environ. Entomol. 35: 813-826.

Kim, K. S., T. W. Sappington, and C. T. Allen. 2008. Genetic profiling to determine potential origins of boll weevils (Coleoptera: Curculionidae) captured in a Texas eradication zone: endemicity, immigration, or sabotage? J. Econ. Entomol. 101: 1729-1736.

Kiser, D., and M. Catanach. 2008. Arkansas boll weevil eradication update, 2007, pp. 1130-1146. In Proceedings of the Beltwide Cotton Conferences, 8-11 January 2008, Nashville, TN.

Liewlaksaneeyanawin, C., C. E. Ritland, and Y. A. El-Kassaby. 2002. Inheritance of null alleles for microsatellites in the white pine weevil (Pissodes strobi [Peck] [Coleoptera: Curculionidae]). J. Hered. 93: 67-70.

Onyabe, D. Y., and J. E. Conn. 1999. Intragenomic heterogeneity of a ribosomal DNA spacer (ITS2) varies regionally in the Neotropical malaria vector Anopheles nuneztovari (Diptera: Culicidae). Insect Mol. Biol. 8: 435-442.

Primmer, C. R., A. P. Møller, and H. Ellegren. 1996. A wide-range survey of cross-species microsatellite amplification in birds. Mol. Ecol. 5: 365-378.

Reardon, B. J., and D. W. Spurgeon. 2002. Critical weights of boll weevil (Coleoptera: Curculionidae) larvae in relation to square desiccation and natural mortality. Environ. Entomol. 31: 972-976.

Patrock, R. J., D. J. Schuster, and E. R. Mitchell. 1992. Field evidence for an attractant produced by the male pepper weevil (Coleoptera: Curculionidae). Fla. Entomol. 75: $138-144$

Roehrdanz, R. L. 2001. Genetic differentiation of Southeastern boll weevil and thurberia weevil populations of 
Anthonomus grandis (Coleoptera: Curculionidae) using mitochondrial DNA. Ann. Entomol. Soc. Am. 94: 928-935.

Sappington, T. W., and D. W. Spurgeon. 2000. Variation in boll weevil captures in pheromone traps (Coleoptera: Curculionidae) arising from wind speed moderation by brush lines. Environ. Entomol. 29: 807-814.

Sappington, T. W., A. D. Brashears, M. N. Parajulee, S. C. Carroll, M. D. Arnold, J. W. Norman, Jr., and A. E. Knutson. 2004. Potential for transport of boll weevils (Coleoptera: Curculionidae) to the cotton gin within cotton modules. J. Econ. Entomol. 97: 934-940.

Sappington, T. W., M. D. Arnold, A. D. Brashears, M. N. Parajulee, S. C. Carroll, A. E. Knutson, and J. W. Norman, Jr. 2006. Dispersal of boll weevils (Coleoptera: Curculionidae) from cotton modules before ginning. J. Econ. Entomol. 99: 67-75.

Selkoe, K. A., and R. J. Toonen. 2006. Microsatellites for ecologists: a practical guide to using and evaluating microsatellite markers. Ecol. Lett. 9: 615-629.

Skoda, S. R., S. Pornkulwat, and J. E. Foster. 2002. Random amplified polymorphic DNA markers for discriminating Cochliomyia hominivorax from C. macellaria (Diptera: Calliphoridae). Bull. Entomol. Res. 92: 89-96.

Smith, J. W. 1998. Boll weevil eradication: area-wide pest management. Ann. Entomol. Soc. Am. 91: 239-247.

Spurgeon, D. W. 2003. Age dependence of pheromone production by the boll weevil (Coleoptera: Curculionidae). Environ. Entomol. 32: 31-38.

Spurgeon, D. W., and J. R. Raulston. 2006. Captures of boll weevils (Coleoptera: Curculionidae) in traps associated with different habitats. J. Econ. Entomol. 99: 752-756.

Spurgeon, D. W., J. R. Raulston, O. Z. Zamora, and J. Loera. 1997. Spatial and temporal patterns of boll weevil trap captures in northeastern Mexico, pp. 984-986. In Proceedings of the Beltwide Cotton Conferences, 6-10 January 1997, New Orleans, LA.

Taylor, D. B., A. L. Szalanski, and R. D. Peterson, II. 1996. Identification of screwworm species by polymerase chain reaction-restriction fragment length polymorphism. Med. Vet. Entomol. 10: 63-70.

Tóth, M., I. Ujváry, I. Sivcev, Z. Imrei, I. Szarukán, O. Farkas, Á. Gömöry, E. Gács-Baitz, and W. Francke. 2007. An aggregation attractant for the sugar-beet weevil, Bothynoderes punctiventris. Entomol. Exp. Appl. 122: 125-132.

Tumlinson, J. H., R. C. Gueldner, D. D. Hardee, A. C. Thompson, P. A. Hedin, and J. P. Minyard. 1971. Identification and synthesis of the four compounds comprising the boll weevil sex attractant. J. Org. Chem. 36: 2616 2621.

Weng, Y., P. Azhaguvel, G. J. Michels, Jr., and J. C. Rudd. 2007. Cross-species transferability of microsatellite markers from six aphid (Hemiptera: Aphididae) species and their use for evaluating biotypic diversity in two cereal aphids. Insect Mol. Biol. 16: 613-622.

Westbrook, J. K., R. S. Eyster, and C. T. Allen. 2007. A model evaluation of long-distance dispersal of boll weevils, pp. 337-344. In Proceedings of the Beltwide Cotton Conferences, 9-12 January 2007, New Orleans, LA.

White, T. J., T. Bruns, S. Lee, and J. Taylor. 1990. Amplification and direct sequencing of fungal ribosomal RNA genes for phylogenetics, pp. 315-322. In M. A. Innis, D. H. Gelfand, J. J. Shinsky, and T. J. White [eds.], PCR protocols: a guide to methods and applications. Academic, San Diego, CA.

Wilson, A.C.C., B. Massonnet, J. C. Simon, N. Prunier-Leterme, L. Dolatti, K. S. Llewellyn, C. C. Figueroa, C. C. Ramirez, R. L. Blackman, A. Estoup, and P. Sunnucks. 2004. Cross-species amplification of microsatellite loci in aphids: assessment and application. Mol. Ecol. Notes 4: 104-109.

Zane, L., L. Bargelloni, and T. Patarnello. 2002. Strategies for microsatellite isolation: a review. Mol. Ecol. 11: 1-16.

Zhang, D. X. 2004. Lepidopteran microsatellite DNA: redundant but promising. Trends Ecol. Evol. 19: 507-509.

Received 29 September 2008; accepted 19 December 2008. 